\title{
ROTAÇÃO DE CULTURAS E EFEITO SOBRE OS CUSTOS NA REFORMA DE CANAVIAL NA REGIÃO DA ALTA PAULISTA ${ }^{1}$
}

\author{
Marcos Roberto de Oliveira $\mathrm{Cruz}^{2}$
}

Marcelo Marques de Magalhães ${ }^{3}$

Resumo: O presente trabalho desenvolve uma avaliação da redução de custo na reforma da cultura de cana-de-açúcar com rotação de leguminosa e adubação verde buscando ao mesmo tempo, melhorar a estrutura e fertilidade do solo. A prática de rotação pode fornecer matéria orgânica ao solo e cobertura vegetal no período de pousio, contribuindo para uma melhor retenção de água, fixação de nitrogênio e incremento da produção em relação à reforma de canavial em pousio sem cultivo. O objetivo deste trabalho é avaliar os benefícios financeiros com o cultivo de cultura de crotalária e amendoim com o propósito de melhoramento físico, químico e biológico do solo para o plantio de cana-deaçúcar. Os dados foram obtidos em entrevista direta com o produtor, com levantamento de campo e informações sistematizadas por este. Foi estimado o custo das operações em um período de três anos de cultivo. Os resultados apontaram para elevação dos custos com reforma em rotação com crotalária de cultivo próprio e redução com reforma em rotação com amendoim em cultivo arrendado, ambos oferecendo melhoria na produtividade ao longo dos anos.

Palavras-chave: custos de produção, rotação de culturas, adubação verde, cana-deaçúcar.

\footnotetext{
${ }^{1}$ O presente trabalho é resultado da monografia apresentada na conclusão do Curso de Pós-graduação Latu Sensu em Agronegócio, Campus Tupã, Universidade Estadual Paulista (UNESP).

${ }^{2}$ Aluno do Curso de Pós-Graduação Latu Sensu em Gestão do Agronegócio, Campus Tupã, Universidade Estadual Paulista, E-mail mroberto agro@yahoo.com.br.

${ }^{3}$ Professor Doutor, Campus Tupã, Universidade Estadual Paulista, E-mail: marcelo@tupa.unesp.br.
} 


\section{INTRODUÇÃO}

No plantio da cana-de-açúcar se faz a rotação de culturas para melhorar a qualidade do solo. A monocultura pode ser prejudicial ao solo porque somente extrai nutrientes sem reposição e prejudicava ainda quando a colheita era feita com a queima da palhada. A rotação com adubação verde fornece matéria orgânica, melhora a retenção de água e nutrientes no solo, fornece nitrogênio, reduzindo o uso dos adubos nitrogenados e dá melhores condições de aproveitamento da adubação mineral. Esta prática empregada na reforma do canavial resulta em melhor produtividade, além de complementar a adução mineral - a qual é de grande necessidade em culturas perenes - e trazer benefícios agronômicos (ROSSETTO et al., 2008a).

O fornecimento de matéria orgânica e nitrogênio fixado, a melhor retenção de água no solo e uma boa cobertura vegetal no período de pousio do solo até o próximo plantio da cana, são as principais vantagens do trabalho com a adubação verde, utilizando-se leguminosas em terras de plantio consecutivo de cana-de-açúcar.

A leguminosa tradicionalmente utilizada na Região da Alta Paulista é a crotalária (JORGE et al. 1994). Esta fornece excelente matéria orgânica para o solo e também, pode-se fazer uso de sua fibra para fabricação de papel de boa qualidade, ainda que se considere uma pequena perda de matéria verde que poderia ser incorporada no solo. O papel de fibra de crotalária é usado na indústria de fabricação de cigarro. Atualmente, o cultivo da crotalária vem sendo substituído pelo do amendoim, que tem um ciclo produtivo parecido com o da crotalária, com plantio em Outubro e colheita no mês de Março (JORGE et al. 1994).

Além dos benefícios para o solo, o cultivo do amendoim na reforma do canavial, promove um melhor controle de ervas daninhas e quebra-se o ciclo de diversas pragas de solo, deixando a terra pronta para o plantio direto da cana-de-açúcar, sobre a palhada do amendoim. Como esta é uma época de fim do período das águas, entrando na época de seca, o plantio direto permite maior retenção da umidade no solo. Por outro lado, na reforma de canavial com crotalária, o plantio direto não foi tecnicamente viável, necessitando da incorporação da palhada ao solo antes do plantio da cana-de-açúcar (BOLONHEZI, 1999). 
Normalmente o plantio de crotalária para reforma do canavial é feito pelo produtor da cana-de-açúcar, enquanto o plantio de amendoim é feito mediante o arrendamento para reforma do canavial.

O sistema de arrendamento é oficializado em contrato para o plantio de amendoim, fazendo a entrega da área de reforma do canavial ao arrendatário no mês de Agosto do ano vigente para que ele faça as operações de preparo do solo e plantio até no máximo, no meio do mês de Novembro, para não ocorrer atraso na colheita e entregar a terra já com amendoim colhido no mês de Março, para evitar também, o atraso do plantio da cana-de-açúcar.

No arrendamento, o produtor de amendoim recebe a terra como foi deixada após a colheita da cana-de-açúcar. Portanto as operações de preparo de solo para o plantio do amendoim, incluindo a eliminação da soqueira do canavial e a manutenção das curvas em nível, ficam todas por conta do arrendatário. Por outro lado, este não paga a renda sobre a terra ao cedente. Do ponto de vista do produtor de amendoim, a maior disponibilidade de terras aptas ao cultivo deste, melhora o aproveitamento do maquinário, que ficaria subutilizado na ausência de terras para o cultivo. Como o contrato é de curto prazo, a princípio parece que não há desvantagens sobre o arrendamento de terras para o plantio do amendoim em rotação de cultura com a cana-de-açúcar.

O objetivo principal deste trabalho é comparar os benefícios financeiros da reforma do canavial feito com o cultivo de crotalária, sob responsabilidade do produtor da cana-deaçúcar, com os benefícios gerados pelo cultivo do amendoim para reforma do canavial em regime de arrendamento. Esta comparação foi realizada por meio de um estudo de caso, em uma propriedade produtora de cana-de-açúcar no município de Valparaíso-SP.

O solo das regiões de expansão da cana-de-açúcar, como em Valparaiso-SP normalmente são caracterizados por baixo nível de matéria orgânica. (ROSSETTO et al., 2008a). No Estado de São Paulo, responsável por 58\% da cana-de-açúcar produzida no país, a expansão ocorreu principalmente pela substituição de áreas de pastagem degradadas (MACEDO, 2007). A área plantada com cana-de-açúcar é de 2,8 milhões de hectares e atualmente ocupa apenas cerca de $2 \%$ da área agrícola do país.

A cultura de cana-de-açúcar é exigente em nutrientes. Quando cultivada em solo com baixa fertilidade natural, começa a apresentar sinais de queda na produtividade já a partir da segunda safra, agravando-se daí em diante (JORGE et al. 1994). É preciso 
recuperar a fertilidade do solo incorporando matéria orgânica por meio de rotação de culturas com objetivo específico de adubação verde ou com leguminosas, naturalmente fixadoras de nitrogênio.

A contribuição desse trabalho está justamente na orientação ao produtor, quando da tomada de decisão sobre as alternativas das culturas que podem ser utilizadas como adubação verde na reforma do canavial.

O trabalho está organizado em 4 seções, além da introdução. Na segunda seção é apresentada uma revisão sobre rotação de culturas em reforma de canavial, com atenção voltada para amendoim e crotalária. Na terceira, apresenta-se a metodologia utilizada para levantamento e contabilização dos custos operacionais para as respectivas culturas. Os resultados são discutidos em detalhe na seção. Na última seção são apresentadas as conclusões do trabalho.

\section{REVISÃO BIBLIOGRÁFICA}

Apresenta-se a seguir uma breve revisão agronômica sobre a rotação de culturas em reforma de canaviais seguida de uma revisão sobre o cultivo da crotalária e amendoim com o mesmo propósito.

\subsection{CANA-DE-AÇÚCAR}

A cana-de-açúcar é uma cultura de múltiplo uso - cumpre o papel de volumoso na alimentação animal, de matéria-prima na fabricação de rapadura, melaço, aguardente, açúcar e etanol, e seu bagaço pode ser queimado para produção de energia elétrica. É uma cultura que se desenvolve bem em clima tropical. O período mais frio no fim do ciclo vegetativo, de Maio a Agosto, promove sua maturação natural incrementando a produção de sacarose (JORGE et al. 1994).

A cana-de-açúcar tem sistema radicular profundo, com ciclo vegetativo médio de cinco safras e intensa mecanização na manutenção da cultura entre as colheitas. Trata-se de uma cultura perene, portanto o planejamento operacional é tratado em três períodos 
distintos: (i) o preparo do solo com plantio subsequente; (ii) a manutenção do canavial e; (iii) a colheita. Cada produtor segue seu próprio itinerário de preparo de solo. As variações ocorrem de acordo com o tipo de solo predominante e a disponibilidade de máquinas e implementos a serem empregados nas operações. A compactação de solos em solos argilosos é um problema comum em canaviais mais velhos. Em áreas de primeira implantação da cultura de cana-de-açúcar utiliza-se uma aração com antecedência ao plantio, para incorporação dos restos culturais existentes. Em seguida faz-se uma gradeação para complementar a primeira operação. Nas áreas de reforma de canavial, a primeira operação é a eliminação das soqueiras de cana, feita após a colheita anterior. Esta operação pode ser feita com uma grade pesada, com enxadas rotativas ou utilizando-se herbicida. Caso seja detectada a ocorrência de compactação, a subsolagem é feita em seguida. A próxima operação é uma aração seguida de gradeação niveladora para manter o solo destorroado, pronto para o plantio. É preciso fazer análise de solo para verificar a necessidade de calagem e adubação (RAlJ et al. 1992).

\subsection{ROTAÇÃO DE CULTURAS EM REFORMA DE CANAVIAIS}

MONTEIRO (1988) afirma que diversos fatores influenciam na escolha da espécie a ser plantada como cultura de rotação para adubação verde e que deve-se dar preferência às leguminosas, por fixarem nitrogênio atmosférico em suas raízes, por possuírem uma estreita relação entre carbono e nitrogênio e por deixarem no solo uma matéria orgânica facilmente decomponível.

Para RODRIGUES (1987) a rotação de culturas em reforma de canavial promove ainda o combate indireto a pragas, como diatrea e elasmo (normalmente sem hospedam em plantas daninhas como áreas de refúgio), aumento da produtividade da cana-deaçúcar e a produção de alimentos.

Segundo MONTEIRO (1988), o amendoim assim como a soja, possui um sistema radicular bem desenvolvido e adapta-se bem a solos arenosos, apresentando um produto de melhor qualidade e com melhores preços no mercado, quando plantado neste tipo de solo. Além disso, é resistente a nematoides causadores de galhas (gênero Meloidogyne) e não causa aumento da população de Pratylenchus no solo, constituindo-se na espécie 
mais indicada para áreas que se apresentam infetada. MONTEIRO e FERREIRA (1986) comentam que o amendoim e a soja exerceram eficiente controle sobre a tiririca, num podzólico vermelho - amarelo que apresentava alta infestação desta planta daninha em Piracicaba - SP.

\subsection{CROTALÁRIA E AMENDOIM}

A crotalária é uma planta de origem indiana com fácil adaptação em países tropicais e esta tem sido utilizada com sucesso em rotação de culturas em reforma de canaviais. A crotalária contribui para o controle de erosão e para a redução do assoreamento no sulco de plantio da cana-de-açúcar quando ocorrem fortes precipitações pluviométricas. Contribui para melhoria da germinação, retenção de água no solo, redução da incidência de plantas daninhas, fixação de nitrogênio evitando o uso de fertilizantes nitrogenados e fornecimento de matéria orgânica. Esse conjunto de benefícios agronômicos contribuem ao final, para o aumento da produtividade (GLORIA et al., 1980).

O cultivo do amendoim requer um solo com um bom preparo para o plantio. O solo deve ser bem revolvido e a cultura é mantida com o mínimo possível de plantas daninhas. Por isso as práticas conservacionistas para o controle de erosão, como o plantio em nível, são de grande importância.

O plantio do amendoim em reforma de canaviais pode contribuir com a produtividade e proporcionar a redução de custos na produção de cana-de-açúcar (LOMBARDI et al., 1987). Nesta rotação, o plantio do amendoim deve ser realizado entre Setembro e Outubro, para que a colheita seja feita até Fevereiro do ano seguinte, liberando o terreno para o plantio da cana-de-açúcar em Março.

Além das vantagens já apontadas, há maior contenção de água, proporcionada pela maior quantidade de material orgânico disponível no momento do preparo de solo para o plantio dos cultivos em rotação. Amostras de solo retiradas em três profundidades (0-15; 16-30 e 31-45 cm) mostraram um conteúdo de água de 10 a 50\% maior nas áreas após amendoim, do que nas áreas após milho (MANHÃES et al., 1983). 


\section{METODOLOGIA}

Este trabalho foi feito por meio de um estudo de caso de uma propriedade rural especializada na produção de cana-de-açúcar. A descrição da propriedade é apresentada no tópico a seguir, com a subsequente descrição dos materiais e métodos empregados para levantamento e análise dos dados.

\subsection{DESCRIÇÃO DA PROPRIEDADE}

A propriedade utilizada neste estudo de caso está localizada no município de Valparaiso-SP. Encontra-se aproximadamente a $600 \mathrm{Km}$ da capital paulista, $30 \mathrm{Km}$ da sede municipal e $9 \mathrm{Km}$ da destilaria para a qual fornece matéria-prima. $A$ área de produção destinada para cana-de-açúcar é de 900 ha, ocupada com as variedades RB 86.7515, RB 96.6928, RB 93.5744 ${ }^{4}$. O relevo médio do terreno é de $16 \%$ de declividade, com solo de textura média em $85 \%$ da propriedade e arenoso nos $15 \%$ restantes.

A propriedade tinha sua atividade econômica voltada para a produção de pecuária de corte e leite, milho, arroz e um haras até 1979. Por ser uma atividade econômica mais rentável, deu início à produção de cana-de-açúcar em seguida, fazendo um canteiro para expansão desta e reduzindo a pastagem destinada à pecuária de corte e de leite, extintas no inicio década de 90. Quando passou por um período de escassez de crédito, a propriedade foi arrendada para uma usina canavieira. Com o fim do contrato de arrendamento e com novas perspectivas para o setor, o produtor retomou a produção de cana-de-açúcar em 1996, mantendo produtividade média em torno de 75 t/ha.

A rotação de culturas na reforma do canavial sempre foi uma prática da propriedade. As culturas que já se cultivou para uso em rotação foram: soja, milho, sorgo e amendoim. Com objetivo de adubação verde trabalhou-se com as seguintes leguminosas: crotalária, mucuna-preta e feijão lab-lab.

\footnotetext{
${ }^{4}$ As variedades RB são desenvolvidas pela Rede Interuniversitária para o Desenvolvimento do Setor Sucroalcooleiro do Brasil (RIDESA).
} 


\subsection{MATERIAL E MÉTODOS}

A estratégia para realizar este estudo foi fazer o levantamento de dados em duas etapas. Primeiro foram levantadas as operações necessárias ao cultivo para as três culturas relacionadas ao trabalho, cana-de-açúcar, crotalária e amendoim. Num segundo momento foram levantados os custos de produção para as mesmas culturas. Os dados foram obtidos diretamente com o produtor responsável pela propriedade por meio de entrevista direta e referem-se ao período de 2010 a 2012. A reforma do canavial foi feita com crotalária em 2012 e com amendoim em 2010, 2011 e 2012. custos.

Neste trabalho, foi feita a ordenação das operações de cultivo conforme o calendário agrícola sincronizado entre as culturas de cana-de-açúcar e, crotalária ou amendoim, visando a reforma do canavial, no período de 2010 a 2012. Esta ordenação tem como referencia o conceito de itinerário técnico, no qual considera-se que as operações estão organizadas em uma sequência lógica e ordenada. Este pode ser aplicado a uma cultura, consórcio de culturas, ou sucessão de cultivos GARCIA (2002).

O levantamento dos custos teve como referência a estrutura de custos de produção utilizada pelo Instituto de Economia Agrícola de São Paulo (IEA), desenvolvida por MATSUNAGA (1976) e aperfeiçoada ao longo dos anos (MELLO, 1978) com sua atualização mais recente por NACHILUKE e OLIVEIRA (2012).

Nas operações foi considerada a potência das máquinas e a capacidade dos implementos, assim como o uso de mão de obra, e a quantidade de insumos utilizados, como adubo, herbicida e inseticida. Foi feita a coleta dos respectivos preços e quantidades utilizadas e posteriormente, o cálculo da parcela que se refere ao custo operacional efetivo (COE). Para calcular o custo operacional total (COT), adicionou-se aos custos operacionais efetivos, os custos indiretos da produção: seguro, encargos financeiros para custeio, contribuição a seguridade social rural, formação da cultura perene quando for o caso, e outras despesas quando pertinentes.

\section{RESULTADOS}


Apresenta-se a seguir a descrição das operações agrícolas para o cultivo da canade-açúcar com a rotação de cultura de crotalária e amendoim e na seção posterior, os respectivos custos operacionais, com análise focalizada na reforma do canavial.

\subsection{DESCRIÇÃO DAS OPERAÇÕES DE CULTIVO}

Primeiro apresenta-se o sistema de cultivo da cana-de-açúcar, posteriormente é relatado o cultivo da crotalária, utilizada como adubação verde na reforma do canavial desde o ano de 1984 e a cultura do amendoim, cultivada por um arrendatário.

\subsubsection{Cana-de-açúcar}

O cultivo da cana-de-açúcar inicia-se com o plantio no mês de Março. O preparo de solo para o plantio convencional é feito com uma ou duas gradeações, uma subsolagem se for preciso, uma aração para incorporação da sobra da cultura anterior e o revolvimento da terra por meio de uma gradeação niveladora. A sulcação vem em seguida acompanhada da distribuição de fertilizantes. Depois distribui-se a muda (semente) e aplica-se inseticida para controle de pragas de solo e aduba-se com micro-nutrientes fechando-se o sulco em seguida. A colheita é feita nos meses de Maio a Novembro do ano seguinte, praticamente entre 13 e 18 meses após o plantio. A produtividade obtida em 2012 após reforma foi de 113,4 t/ha, enquanto a esperada para o primeiro corte é de 120 t/ha (JORGE et al., 1994). Após o primeiro corte se faz as adubações de manutenção do canavial de acordo com análise de solo até o $5^{\circ}$ ou $6^{\circ}$ corte, que daria 6 anos de cultivo chegando ao fim de sua vida útil. É neste ponto que se entra novamente com adubação verde para a reforma do canavial.

\subsubsection{Crotalária}


O preparo de solo é feito entre Setembro e Novembro, logo após a colheita da cana-de-açúcar, incorporando-se os restos da cultura com uma ou duas gradeações, aração do solo e uma gradeação niveladora. A semeadura é feita com um distribuidor de sementes e em seguida se passa uma grade niveladora para cobertura das sementes. Após a germinação faz-se o controle de ervas daninhas e pragas. A produção esperada de matéria seca para adubação verde está entre 10 a 15 t/ha segundo JORGE et al. (1994). A produção esperada para extração de fibras é de 2,5 a 3,5 t/ha. Se o objetivo fosse a produção de sementes, esta seria de 500 a $1.000 \mathrm{Kg} / \mathrm{ha}$ (JORGE et al. 1994). A crotalária é incorporada ao solo entre Fevereiro e Março para o plantio do próximo cultivo de cana-de-açúcar.

\subsubsection{Amendoim}

O cultivo do amendoim em reforma de canavial inicia-se com a eliminação da soqueira do canavial com uma gradeação pesada, a qual também incorpora o calcário. Se necessário, faz-se uma subsolagem para descompactação do solo. A finalização da incorporação dos restos da cultura anterior é realizada com uma aração para o revolvimento do solo. É feito o nivelamento do terreno com uma grade niveladora, destorroando o solo para a adubação de plantio. O plantio para reforma do canavial é feito nos meses de Setembro a Outubro, esperando-se uma produção de 4.000 a $4.700 \mathrm{Kg} / \mathrm{ha}$. O controle de ervas daninhas é feito após a germinação do amendoim. O controle de insetos e doenças fúngicas é feito de acordo com o clima e a ocorrência. Utiliza-se um pulverizador de barras acoplado ao trator. A colheita é feita com a chacoalhadeira de amendoim. Esta inverte a planta na superfície do solo promovendo uma secagem parcial. Após a secagem, é utilizada a trilhadora de reservatório de descarga no transbordo para separação da vagem do amendoim do resto da parte aérea. Em todas as operações se faz uso de tratores com potência acima de $100 \mathrm{cv}$.

\subsection{CUSTOS DE PRODUÇÃO}




\section{Sand

O objetivo do estudo de custos é comparar as alternativas de rotação de culturas para na reforma do canavial. Na Tabela 1 apresenta-se a evolução da área plantada das culturas em rotação e do cultivo da cana-de-açúcar nos anos de 2010 a 2012 . Também foi apresentada a área em manutenção entre cortes, como informação adicional sobre a estratégia adotada pelo produtor no planejamento para condução da cultura no longo prazo.

O cultivo do amendoim é realizado no sistema de arrendamento, no qual o arrendatário não paga diretamente pelo arrendamento, mas tem como obrigação deixar a terra pronta para o plantio de um novo canavial após a colheita do amendoim. Os custos operacionais para cada cultura são apresentados nas seções a seguir, respectivamente para cana-de-açúcar, crotalária e amendoim.

Tabela 1. Sumário das operações agrícolas para o cultivo de cana-de-açúcar, com detalhamento para reforma de canavial em rotação com crotalária e amendoim, 2010, 2011 e 2012.

\begin{tabular}{lccc}
\hline \multirow{2}{*}{ Atividades } & \multicolumn{3}{c}{ Área em (ha) } \\
\cline { 2 - 4 } & 2010 & 2011 & 2012 \\
\hline Reforma sem rotação & 0 & 0 & 0 \\
Reforma com crotalária & 50 & 200 & 50 \\
Reforma com amendoim & 100 & 150 & 100 \\
Plantio de cana & 150 & 350 & 150 \\
Manutenção do canavial & 750 & 550 & 750 \\
\hline Área ocupada com canavial (ha) & 900 & 900 & 900 \\
\hline
\end{tabular}

Fonte: Levantamento de campo, 2013.

\subsubsection{Cana-de-açúcar}

A análise comparativa de custos na reforma do canavial requer o desdobramento dos custos em 3 etapas. Primeiro fez-se o detalhamento dos custos do preparo de solo, que refere-se à reforma do canavial sem rotação, seguido do plantio e dos custos anuais de manutenção entre cortes realizados em 6 anos de colheita.

A reforma do canavial sem rotação de culturas não foi realizada no período utilizado para análise da reforma com rotação de culturas. Os custos apresentados nas Tabelas 2, 3 e 4 foram obtidos por estimativa, utilizando-se uma adaptação entre recomendações para a cana-de-açúcar, as práticas tradicionalmente realizadas na 
propriedade e o preços dos serviços e insumos respectivos aos anos de 2010, 2011 e 2012.

O custo do preparo de solo por hectare variou entre $R \$ 648,00, R \$ 676,10$ e $\mathrm{R} \$ 707,92$, para os anos de 2010, 2011 e 2012 (Tabela 2). Esses valores foram utilizados como referência para a comparação entre os custos da reforma em rotação com crotalária e amendoim. Em termos de custos, as operações mais importantes para o preparo do solo são aração, gradeação pesada e subsolagem, representado pouco mais de $75 \%$ do custo total em 2010. Essa porcentagem permanece quase a mesma nos seguintes por conta dos aumentos proporcionais para as demais operações (Tabela 2).

No plantio os principais itens de custos são mão de obra, sementes e adubação, representando até $80 \%$ dos custos no plantio em 2010. Este valor sobe para $86 \%$ em 2011 porque o aumento de preços foi maior para os fertilizantes (Tabela 3). Este padrão foi mantido em 2012.

Na etapa de manutenção do canavial, a maior parcela do custo está na adubação, representando 74\% desta operação em 2011 (Tabela 4).

Tabela 2. Custos para o preparo de solo de 1 hectare de cana-de-açúcar, em cultivo de 18 meses, com produção esperada de 80t/ha em média para o total de 6 cortes, município de Valparaiso-SP, Março de 2010, 2011 e 2012.

\begin{tabular}{lrrrrrrr}
\hline \multirow{2}{*}{ Operações } & \multirow{2}{*}{$\begin{array}{c}\text { Horas/ } \\
\text { ha }\end{array}$} & $\begin{array}{c}\text { Valor/ } \\
\text { Hora (R\$) }\end{array}$ & $\begin{array}{c}\text { Valor } \\
\text { Total (R\$) }\end{array}$ & $\begin{array}{c}\text { Valor/ } \\
\text { Hora (R\$) }\end{array}$ & $\begin{array}{c}\text { Valor } \\
\text { Total (R\$) }\end{array}$ & $\begin{array}{c}\text { Valor/ } \\
\text { Hora (R\$) }\end{array}$ & $\begin{array}{c}\text { Valor } \\
\text { Total (R\$) }\end{array}$ \\
\hline Gradeação pesada (2x) & 1,30 & 120,00 & 156,00 & 124,29 & 161,58 & 129,16 & 167,96 \\
Subsolagem & 1,30 & 120,00 & 156,00 & 124,29 & 161,58 & 129,16 & 167,96 \\
Aração & 2,20 & 80,00 & 176,00 & 84,29 & 185,44 & 88,45 & 194,59 \\
Calagem & 0,25 & 40,00 & 10,00 & 44,29 & 11,07 & 53,00 & 13,25 \\
Manutenção de terraços & 1,00 & 120,00 & 120,00 & 124,29 & 124,29 & 129,16 & 129,16 \\
Gradeação niveladora (2x) & 0,50 & 60,00 & 30,00 & 64,29 & 32,15 & 70,00 & 35,00 \\
\hline Total & & & $\mathbf{6 4 8 , 0 0}$ & & $\mathbf{6 7 6 , 1 0}$ & & $\mathbf{7 0 7 , 9 2}$ \\
\hline
\end{tabular}

Fonte: Levantamento de campo, 2013. 
Tabela 3. Custos para o plantio de 1 hectare de cana-de-açúcar, em cultivo de 18 meses, com produção esperada de 80t/ha em média para o total de 6 cortes, município de Valparaiso-SP, Março de 2010, 2011 e 2012.

\begin{tabular}{lrrr}
\hline \multirow{2}{*}{ Itens } & \multicolumn{3}{c}{ Valores (R\$) } \\
\cline { 2 - 4 } & $\mathbf{2 0 1 0}$ & $\mathbf{2 0 1 1}$ & $\mathbf{2 0 1 2}$ \\
\hline Sulcação & 100,00 & 110,00 & 121,00 \\
Cobrição & 15,00 & 16,50 & 18,10 \\
Adubação & 550,00 & 750,00 & 820,00 \\
Mão de obra & 900,00 & $1.000,00$ & $1.050,00$ \\
Mudas/semente & 600,00 & 800,00 & 900,00 \\
Inseticida & 125,00 & 150,00 & 159,00 \\
Nematicida & 80,00 & 85,00 & 92,00 \\
Micros Nutrientes & 65,00 & 95,00 & 102,00 \\
Herbicida & 100,00 & 140,00 & 155,50 \\
\hline Total & $\mathbf{2 . 5 3 5 , 0 0}$ & $\mathbf{3 . 1 4 6 , 5 0}$ & $\mathbf{3 . 4 7 7 , 6 0}$ \\
\hline
\end{tabular}

Fonte: Levantamento de campo, 2013.

Tabela 4. Custos para 1 hectare de manutenção e operação do Canavial Entre Cortes, Julho a Novembro, 2010, 2011 e 2012.

\begin{tabular}{lrrr}
\hline \multirow{2}{*}{ Itens } & \multicolumn{3}{c}{ Valores (R\$) } \\
\cline { 2 - 4 } & $\mathbf{2 0 1 0}$ & $\mathbf{2 0 1 1}$ & $\mathbf{2 0 1 2}$ \\
\hline Adubação & 590,20 & 680,00 & 760,20 \\
Herbicidas & 142,5 & 150,00 & 158,00 \\
Capina & 48,00 & 60,00 & 82,00 \\
Controle Biológico & 25,00 & 30,00 & 37,10 \\
\hline Total & $\mathbf{8 0 5 , 0 0}$ & $\mathbf{9 2 0 , 0 0}$ & $\mathbf{1 . 0 3 7 , 3 0}$ \\
\hline
\end{tabular}

Fonte: Levantamento de campo, 2013.

\subsubsection{Crotalária}

O custo operacional no cultivo da crotalária atinge os valores de $\mathrm{R} \$ 955,16$, $\mathrm{R} \$ 1.007,09$ e $\mathrm{R} \$ 1.075,88$, por hectare para os anos de 2010, 2011 e 2012 (Tabela 5). O principal fator de pressão no custo operacional vem do aumento dos preços dos combustíveis que afetaram diretamente o preparo de solo. Segundo a estrutura de custos operacionais, o preparo de solo tem como principais operações a gradeação pesada, a aração e a subsolagem, que juntas representaram perto de $80 \%$ do custo do cultivo de crotalária, para os três anos em análise. Os insumos, como sementes e calcário, representaram $20 \%$ desses custos. No sistema de cultivo visando a adubação verde não houve adubação de plantio e ou de cobertura para a crotalária. 
Tabela 5. Custo do preparo de solo e plantio de um 1 hectare para o cultivo de crotalária para adubação verde, Setembro a Novembro, 2010, 2011 e 2012.

\begin{tabular}{lrrrrrrr}
\hline \multirow{2}{*}{ Operações } & \multirow{2}{*}{$\begin{array}{c}\text { Horas/ } \\
\text { ha }\end{array}$} & \multicolumn{2}{c}{$\mathbf{2 0 1 0}$} & \multicolumn{2}{c}{$\mathbf{2 0 1 1}$} & \multicolumn{2}{c}{$\mathbf{2 0 1 2}$} \\
\cline { 3 - 9 } & & $\begin{array}{c}\text { Valor/ } \\
\text { Hora (R\$) }\end{array}$ & $\begin{array}{c}\text { Valor } \\
\text { Total (R\$) }\end{array}$ & $\begin{array}{c}\text { Valor/ } \\
\text { Hora (R\$) }\end{array}$ & $\begin{array}{c}\text { Valor } \\
\text { Total (R\$) }\end{array}$ & $\begin{array}{c}\text { Valor/ } \\
\text { Hora (R\$) }\end{array}$ & $\begin{array}{c}\text { Valor } \\
\text { Total (R\$) }\end{array}$ \\
\hline Gradeação pesada (2x) & 2,4 & 120,00 & 288,00 & 124,29 & 298,29 & 129,16 & 309,98 \\
Subsolagem & 1,3 & 120,00 & 156,00 & 125,00 & 162,50 & 129,16 & 167,91 \\
Aração & 2,2 & 70,30 & 154,66 & 79,10 & 174,02 & 88,45 & 194,59 \\
Gradeação niveladora (2x) & 0,5 & 55,00 & 27,50 & 60,10 & 30,05 & 68,48 & 34,24 \\
Calagem & 0,5 & 31,00 & 15,50 & 36,50 & 18,25 & 40,00 & 20,00 \\
Manutenção de terraços & 1 & 120,00 & 120,00 & 125,00 & 125,00 & 129,16 & 129,16 \\
Plantio da crotalária (1) & 0,5 & 387,00 & 193,50 & 398,00 & 199,00 & 440,00 & 220,00 \\
\hline Total & & & $\mathbf{9 5 5 , 1 6}$ & & $\mathbf{1 . 0 0 7 , 0 0}$ & & $\mathbf{1 . 0 7 5 , 8 8}$ \\
\hline
\end{tabular}

Notas: (1) Considera-se $30 \mathrm{Kg} / \mathrm{ha}$ sementes, ao preço por $\mathrm{Kg}$ de $\mathrm{R} \$ 5,00$ em 2010, R\$6,00 em 2011 e $\mathrm{R} \$ 7,00$ em 2012.

Fonte: Levantamento de campo, 2013.

\subsubsection{Amendoim}

Os dados de custos da produção de amendoim referem-se somente ao ano de 2012. Esta cultura é de responsabilidade do arrendatário e o contrato de arrendamento é anual. A troca de arrendatários ao longo dos anos impossibilitou a recuperação de informações anteriores.

Em 2012 a estrutura de custos do amendoim foi marcada pelo alto valor dispendido em agroquímicos (fungicidas, inseticidas e fertilizantes), chegando a $74 \%$ do custo operacional de produção. O preparo de solo respondeu por $20 \%$ dos custos de produção (Tabela 6). $O$ saco de $25 \mathrm{Kg}$ de amendoim em casca chegou a ser vendido a $R \$ 26,00$ no começo da safra de 2012, mês de março. Nos anos anteriores, 2010 e 2011, os preços chegaram, a $R \$ 40,00$ e $R \$ 30,00$ por saco. Na pior das hipóteses, o produtor de amendoim, obteria uma receita bruta de $R \$ 4.784,00 /$ ha em 2012, considerando-se que os $\mathrm{R} \$ 26,00 /$ saco de $25 \mathrm{Kg}$ já inclui limpeza, secagem e o frete de entrega do produto processado. Em termos líquidos, a receita mínima seria de $\mathrm{R} \$ 1.288,80$ por hectare (Tabela 6).

Embora não se tenha dados detalhados envolvendo as operações, custos e receitas para uma análise mais precisa, observou-se que o cultivo do amendoim proporcionou aumento de $5 \%$ na produtividade de cana-de-açúcar de primeiro corte nas 
áreas reformadas em 2011 em comparação com a produtividade do primeiro corte obtida nas áreas reformadas em 2010. Por outro lado, foi observada deficiência hídrica na cultura de cana-de-açúcar em toda a área (900 ha) de Junho a Outubro de 2010, evento que não ocorreu nos anos subsequentes, de 2011 e 2012. Este evento pode ter afetado os ganhos de produtividade observados entre 2010 e 2011, mas seguramente não afetou os ganhos observados entre 2011 e 2012, de aproximadamente 8\% (Tabela 7). Não foram coletados dados sobre evolução da produtividade em área de rotação com crotalária.

Tabela 6. Custo do preparo de solo, plantio e tratos culturais para 1 hectare de amendoim com produção esperada de $4.600 \mathrm{Kg} / \mathrm{ha}, 2012$.

\begin{tabular}{lr}
\hline Itens & Valor (R\$) \\
\hline Preparo de solo & 680,20 \\
Plantio & 45,00 \\
Adubo & 600,00 \\
Sementes & 150,00 \\
Herbicida & 120,00 \\
Fungicida & 920,00 \\
Inseticida & 980,00 \\
\hline Total & $\mathbf{3 . 4 9 5 , 2 0}$ \\
\hline
\end{tabular}

Fonte: Levantamento de campo, 2013.

Tabela 7. Evolução da produtividade de cana-de-açúcar em áreas de rotação com amendoim, 2010 a 2012.

\begin{tabular}{lccc}
\hline \multirow{2}{*}{ Itens } & \multicolumn{3}{c}{ Produtividade (t/ha) } \\
\cline { 2 - 4 } & $\mathbf{2 0 1 0}$ & $\mathbf{2 0 1 1}$ & $\mathbf{2 0 1 2}$ \\
\hline Cana de açúcar & 100,0 & 105,0 & 113,4 \\
\hline Fonte: Levantamento de campo, 2013. & & &
\end{tabular}

Fonte: Levantamento de campo, 2013.

\subsection{COMPARAÇÃO ENTRE REFORMA CONVENCIONAL E ROTAÇÕES}

O cultivo da crotalária como adubação verde promoveu a elevação dos custos em relação à reforma do canavial em pousio, mas com benefícios agronômicos esperados no longo prazo. O aumento no custo operacional da reforma foi de $47 \%$, $49 \%$ e $52 \%$, para os anos de 2010, 2011 e 2012, respectivamente. 
Os dados para o cultivo do amendoim em rotação permitem comparação somente para o ano de 2012. Para este ano, o custo do cultivo foram 3,5 vezes maior que o custo da reforma com rotação de crotalária e 5 vezes maior que o custo da reforma do canavial em pousio (sem rotação). Como o cultivo foi feito pelo arrendatário, o custo para o produtor de cana-de-açúcar foi nulo.

A rotação de cultura com amendoim seria ainda mais vantajosa se o cultivo deste fosse feito pelo próprio produtor de cana-de-açúcar. Os resultados obtidos nesta pesquisa seguem alinhados com os resultados obtidos por LOMBARDI et al. (1987), que contabilizou aumento na receita líquida de 26 e 48\% quando se utilizou, respectivamente, crotalária como adubação verde e amendoim como cultura alimentícia.

\section{CONCLUSÃO}

O sistema de produção de cana-de-açúcar com cultivo convencional sem rotação de cultura, ou seja, com reforma em pousio, provoca a crescente perda de produtividade ao longo dos anos devido à perda na fertilidade natural do solo e dificuldade no controle de ciclo de pragas de solo, características típicas dos principais problemas em monoculturas.

A prática de rotação de culturas com leguminosas aumenta os custos operacionais para o produtor, por outro lado, promove um amplo conjunto de benefícios agronômicos para recuperação da produtividade. Contribui para a quebra de ciclo de pragas de solo, fornecimento de matéria orgânica, fixação de nitrogênio trazendo redução de uso dos fertilizantes nitrogenados no cultivo do canavial, e destacando a produção de outra cultura como o amendoim em solo no período de pousio. Os resultados obtidos permitiram avaliar que a rotação de culturas contribuiu, mesmo que parcialmente, com a elevação na produtividade, sem investimentos adicionais e sem pressão sobre os demais custos operacionais.

A reforma do canavial feita com cultivo de crotalária para adubação verde elevou os custos operacionais em cerca de 50\%, oferecendo no longo prazo, os benefícios agronômicos necessários ao cultivo da cana-de-açúcar. Este processo de recuperação da fertilidade seguramente será compensado ao longo dos anos. 


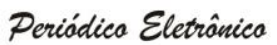

O cultivo do amendoim, em rotação na reforma do canavial apresentou-se como uma alternativa mais interessante ao produtor de cana-de-açúcar. Esta oferece os benefícios agronômicos almejados sem o mesmo efeito final sobre os custos operacionais da reforma canavial promovido pelo cultivo da crotalária. $O$ amendoim cultivado por arrendatário praticamente promove a anulação dos custos de preparo de solo na reforma do canavial. Embora não tenha sido feito levantamento sobre os custos de investimento em máquinas e equipamentos específicos para o cultivo do amendoim e sobre os riscos envolvidos nos custos operacionais deste, observou-se que a cultura poderia trazer um rendimento líquido positivo ao produtor de cana-de-açúcar, se este optasse pelo cultivo próprio do amendoim.

A adoção da prática de rotação com a cultura do amendoim poderia ser incrementada nas áreas de reforma de cana-de-açúcar de ano e meio, pois as vantagens agronômicas também se realizam em termos econômicos.

\section{REFERÊNCIAS}

BOLONHEZI, D. P. J.C.N.A. Plantio Direto na Alta Mogiana. O Agronômico. Campinas: B. Tecnico Informativo do Instituto agronômico v. 51, p 12-15, 1999.

GARCIA, D. P. Análise de diagnósticos de sistema agrários: guia metodológico. Brasília: Projeto de Cooperação Técnica INCRA/FAO (UTF/BRA/051), 2002. 61p.

GLORIA, N, A.; MATTIAZO, ME; PEREIRA, V. PARO, J. M. Avaliação da produção de adubos verdes v, 3, n.8, p. 31-35,1980.

JORGE, J. A.; LOURENÇÃO, A. L. ARANHA, C. Instruções agrícolas para o Estado de São Paulo. 2. Impressão. Série Boletim Técnico do Instituto Agronômico. Campinas: IAC. n.200, 5ª Edição, 1994. 233p. ISSN 0375-1538.

LOMBARDI, A.C.; LIMA FILHO, S. A.; RUAS, D.G.G.; GODOY, O.P.; MINAMI, K.; LAVORENTI, N.A. Agricultura energética e produção de alimentos - avaliação preliminar de experimentação da cana-de-açúcar relacionada com milho, feijão, amendoim, arroz e soja no Estado de São Paulo. Brasil Açucareiro, v.99, n.l, p.29-44, 1987

MACEDO, I. C. A energia da cana-de-açúcar, doze estudos sobre a agroindústria da cana-de-açúcar no Brasil e sua sustentabilidade. São Paulo: Berlendis e Vertecchia. ÚNICA (União da Agroindústria Canavieira de São Paulo), 2007. 231p.

MANHÃES, M. S.; CRUZ FILHO, D.J. Avaliação dos rendimentos de leguminosas para adubação verde na zona canavieira do Estado de São Paulo. Saccharum, v.6, n.25, p.4044, 1983. 
MATSUNAGA, M. et. al. Metodologia de custos. In: Informações Econômicas. v 23, t. 1, p. 123,139, 1976.

MONTEIRO. A. O. Rotação de culturas na lavoura canavieira. In: SEMINÁRIO DE TECNOLOGIA AGRONÔMICA, 4., 1988, Piracicaba. Anais... São Paulo: Copersucar, 1988. p.67-95.

MONTEIRO, A. O.; FERREIRA, E.S. Projeto rotação de culturas - principais resultados obtidos. In: SEMINÁRIO DE TECNOLOGIA AGRONÔMICA, 3., Piracicaba, 1986. Anais... São Paulo: Copersucar, 1986. p.87-200.

NACHILUK, K.; OLIVEIRA, M. D. M. Custo operacional e ponto de manutenção e custos de reforma de colhedoras de cana-de-açúcar 2012.

RAIJ, B. V. et al. Recomendações de adubação e calagem para o Estado de São Paulo. 2. Impressão. Série Boletim Técnico do Instituto Agronômico. Campinas: IAC. n. 100, 1992. 107p. ISSN 0100-3100.

ROSSETTO, R; DIAS F. L. R.; VITTI, A. C. Problemas nutricionais dos solos nas fronteiras canavieiras. Revista Idea News, v8 p 78-90 2008a.

ROSSETTO, R.; KORNDORFER, G. H.; DIAS. F. L. Nutrição e adubação da cana-deaçúcar. In: MARQUES, M. O.; MUTTON M. A., NOGUEIRA T. A. R.; TASSO JR. L. C.; NOGUEIRA G. A.; BERNARDI, J. H. Tecnologias na Agroindústria Canavieira. FCAV, Jaboticabal. SP. p 125-139. 2008b. 